\title{
Perspectieven van de buiten- en binnenwacht: de institutionele opgave van de rechtspraak
}

\author{
Suzan Verberk, Paul Frissen, Paul 't Hart \& Stijn Sieckelinck
}

In 2012 heeft de Raad voor de rechtspraak door de Nederlandse School voor Openbaar Bestuur (NSOB) onderzoek laten uitvoeren naar de wijze waarop belangrijke beslissers en opinieleiders in Nederland oordelen over de rechtspraak. Hiermee werd in een belangrijke leemte voorzien. Eerder was via klantwaarderingsonderzoeken en studies zoals die van het Sociaal en Cultureel Planbureau inzicht verkregen in de wijze waarop justitiabelen en de bevolking oordelen over de rechtspraak, maar naar de perceptie van andere belangrijke stakeholders was nog geen systematisch onderzoek gedaan. In deze bijdrage voor Recht der Werkelijkheid staan we in het eerste deel stil bij de belangrijkste bevindingen van het onderzoek. In het tweede deel leggen we deze resultaten naast recente ontwikkelingen in de rechtspraak, met name het verschijnen van het Manifest en de discussie die daarop volgde. Uit deze ontwikkelingen blijkt dat de interne legitimiteit de Rechtspraak wellicht nog voor grotere uitdagingen stelt dan de externe legitimiteit die centraal stond in het onderzoek naar reputatiemanagement. In het derde deel van dit artikel proberen we deze constatering te duiden en presenteren we enkele oplossingsrichtingen.

\section{Onderzoek naar de externe reputatie: achtergrond en methode}

'De externe oriëntatie is voor de rechtspraak belangrijker dan ooit', zo staat geschreven in het programmaplan Rechtspraak en Samenleving van de Raad voor de rechtspraak.

'Rechtspraak is er niet voor zichzelf maar staat ten dienste van de samenleving. Wanneer echter de samenleving een beeld heeft dat schuurt met de werkelijkheid van de rechtspraak, leidt dit naar verwachting tot toenemende reputatieschade. Presidentenvergadering en Raad hebben besloten een programma te starten met diverse projecten en activiteiten die erop gericht zijn het beeld van de rechtspraak naar buiten te verduidelijken en te verbeteren.

Naast dit externe doel kent het programma ook een intern doel: het ontwikkelen van een betere oriëntatie van de rechtspraak op de samenleving.

In dit kader gaf de Raad voor de rechtspraak de NSOB opdracht onderzoek te doen naar de reputatie van de rechtspraak bij beslissers en opinieleiders (hooggeplaatste vertegenwoordigers van de belangrijkste stakeholders van de rechtspraak). Er werd, aan de hand van een semigestructureerde vragenlijst, gesproken met 33 personen. De gesprekspartners waren gekozen met het oog op een gewenste spreiding over relevante maatschappelijke domeinen en partijen, waarbij de 


\section{Figuur 1 Strategische positionering van publieke organisaties}

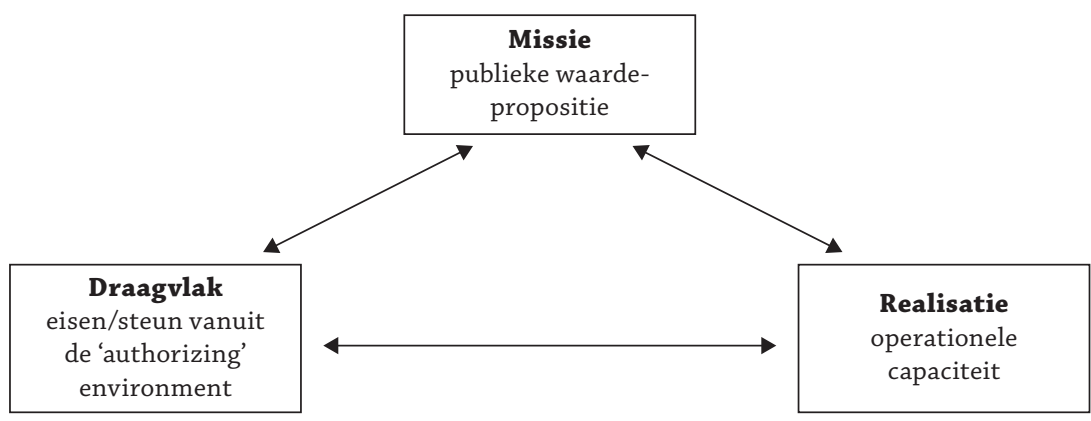

volgende selectie werd gemaakt: politiek (4), openbaar bestuur (7), politie en OM (4), overige ketenpartners (6), adviesorganen (2), bedrijfsleven (2), sociale partners (2), maatschappelijke organisaties (3), en media (3). Inzet was de vraag hoe deze elites het functioneren van de zittende magistratuur ervaren en beoordelen. De resultaten van deze studie zijn gepubliceerd in de serie Research Memoranda van de Raad voor de rechtspraak ${ }^{1}$ en zijn gebruikt als input voor de Rechtspraaklezing van 2012 door Paul Frissen.

\section{De reputatie van de rechtspraak: resultaten op hoofdlijnen}

Van Tulder en Van der Zwart omschrijven reputatie als een 'dynamisch fenomeen dat gestalte krijgt in de relatie en interactie met stakeholders. Een unanieme (...) reputatie is onmogelijk, elke stakeholder maakt immers een beoordeling op basis van een individuele perceptie, eigen ervaringen, belangen en verwachtingen.' Met andere woorden, reputatie betreft het geheel van percepties van de diverse actoren in het relevante netwerk en is per definitie geen statisch gegeven.

Met deze definitie in het achterhoofd is onderzoek gedaan naar de reputatie van de rechtspraak, waarbij drie thema's met de gesprekspartners zijn uitgediept: de maatschappelijke opgave, de operationele capaciteit en de legitimiteit van de Rechtspraak. Deze driedeling is ontleend aan het werk over de creatie van publieke waarden van Moore; de drie thema's vertegenwoordigen tezamen de strategische positionering van publieke organisaties. ${ }^{3}$

\section{De missie van de rechtspraak: kernwaarden en kernfuncties}

Als kernwaarden van de rechtspraak zijn door de geïnterviewden 'onafhankelijkheid', 'onpartijdigheid' en 'integriteit' geïdentificeerd. De kernfunctie wordt door de geïnterviewden enigszins verschillend gedefinieerd, zoals 'het toepassen van 
wet- en regelgeving', 'het doorhakken van lastige knopen' en 'zorgen dat mensen goed met elkaar omgaan'. Onder de geïnterviewden bestaat 'geen enkele twijfel over de publieke waarde van de adequate vervulling van deze functies. Kortom, niemand relativeert het belang van de rechtspraak in de samenleving, integendeel. $^{4}$

2. De operationele capaciteit: het vermogen om kernfuncties effectief te vervullen Het algemene oordeel van de geïnterviewden over het functioneren van rechters is positief. De integriteit, professionaliteit en deskundigheid van de rechter worden positief beoordeeld.

'[T] egelijkertijd plaatst een niet te negeren deel van de ondervraagden kritische kanttekeningen bij de bedrijfsvoering, de niet uitlegbare grote variatie tussen rechters en rechtbanken in uitspraken, bejegeningspraktijken, de externe communicatie (...) en het schijnbaar beperkte zelfreflectieve vermogen (...). ${ }^{5}$

Daarbij geldt dat de actoren die het meest met de rechtspraak in aanraking komen, ook de meeste kritiek op de operationele aspecten uiten. Dat geldt met name voor de categorieën 'politie en OM' en 'andere ketenpartners'. Voorbeelden van zorg en kritiek die daarbij worden geuit, zijn: 'De rechtbank moet oppassen dat die niet achter gaat lopen op een aantal terreinen' en 'Ik heb sterk het idee dat de rechtspraak niet is aangepast aan huidige vraagstukken'. ${ }^{6}$ Bij doorvragen geeft meer dan een kwart van de respondenten kritiek op de operationele capaciteit van de rechtspraak, waarbij met name de doorlooptijden het moeten ontgelden. Ook wordt gewezen op het gebrek aan technologische innovatie. Voorbeelden van citaten die deze kritiek ondersteunen: 'Een groot minpunt is de lange doorlooptijd (...) er kan veel meer digitaal dan nu', 'Eindeloos traag (...) dat je tig keer moet bellen met de griffie' en 'Zonder innovatie zijn we ten dode opgeschreven'. ${ }^{7}$

\section{Het institutionele draagvlak voor de rechtspraak: hoe sterk is het merk?}

Er bestaat onder de respondenten weinig steun voor de ene uiterste stelling dat er helemaal niets mis is met de reputatie van de rechtspraak, noch voor de andere uiterste stelling dat de rechtspraak zich in een reputatiecrisis bevindt. Wel vindt ongeveer twee derde van de respondenten dat de Rechtspraak zich wat meer zorgen zou mogen maken over de beeldvorming die over haar bestaat. Daarbij onderkennen de gesprekspartners de complexe omgeving waarin de Rechtspraak zich bevindt. Een omgeving die, als gevolg van veranderde maatschappelijke opvattingen over gezag, de Rechtspraak niet automatisch het voordeel van de twijfel geeft. ${ }^{8}$ In dit verband wordt regelmatig gerefereerd aan de rol van de media en 
gewezen op gemakzuchtige journalisten. Een van de geïnterviewden stelt: 'De negatieve media-aandacht en het gemak waarmee de politiek achter die publieke kritiek aanloopt, maken dat een veel scherpere en bredere kritiek zich ontwikkelt in het publieke domein dan wanneer je het zou baseren op algemene prestaties. De media bespelen het publieke domein. Er is voornamelijk aandacht voor de zaken die niet goed gaan, die komen onder een vergrootglas. Er komt natuurlijke zelden in de krant dat er een mooie goed lopende beslissing is geweest die goed is gemotiveerd.' ${ }^{\prime}$

\section{Interne onrust}

Het oordeel van de buitenwacht, hoewel niet onverdeeld positief, gaf tegelijkertijd ook geen aanleiding tot zeer grote ongerustheid. Onrust in de organisatie ontstond enkele maanden later wél naar aanleiding van het schrijven van enkele raadsheren uit Leeuwarden dat bekend is komen te staan als 'het Manifest'. ${ }^{10}$ De eerste zin van dit Manifest luidt als volgt: 'Wij maken ons grote zorgen over de organisatie van de rechtspraak en de nadelige gevolgen daarvan voor de interne onafhankelijkheid van de rechters en de kwaliteit van de rechtspraak.' Een van de grieven van de opstellers van het Manifest (dat door bijna dertig procent van de rechters en raadsheren is ondertekend en op begrip kon rekenen van de president van de Hoge Raad blijkens een krantenpublicatie) luidt dat de rechtspraak steeds meer gaat lijken op een groot bedrijf, waar productienormen en budgetten leidend zijn. Daarbij is er volgens de opstellers sprake van een situatie waarbij onverantwoorde keuzes worden gemaakt om aan productie-eisen tegemoet te komen.

Fundamentele kritiek op de Rechtspraak bleek aldus veeleer van binnen dan van buiten te komen. En, vertaald naar de strategische positionering (zie figuur 1), daarmee lijkt niet zozeer het externe draagvlak als wel het interne draagvlak problematisch.

De Raad voor de rechtspraak heeft het signaal dat van het Manifest uitging serieus genomen, zo blijkt uit het feit dat direct na het verschijnen ervan een gesprekkenronde is gehouden waarbij leden van de Raad de gerechten hebben bezocht. Op basis van deze gesprekken met rechterlijke ambtenaren en gerechtssecretarissen heeft de Raad een schriftelijke reactie op het Manifest opgesteld. Daarin constateert de Raad:

'Een deel van de rechters en raadsheren meent dat de Raad voor de rechtspraak onvoldoende tegenwicht biedt aan de almaar groeiende verlangens en eisen van de politiek en samenleving, die ieder op zich begrijpelijk zijn, maar opgeteld een goede beroepsuitoefening in de weg staan.' 
De conclusie die de Raad daaraan verbindt, is dat met betrekking tot de productiedruk er explicieter grenzen dienen te worden gesteld, zowel door de Raad, de gerechtsbesturen als door professionals zelf. Daarbij geldt volgens de Raad dat de kwaliteit van rechtspraak het primaat heeft: 'Als blijkt dat de gerechten, na alle mogelijke maatregelen te hebben genomen, alleen in staat zijn de kwaliteit te handhaven door in de rode cijfers te gaan, dan zij dat zo.'

De leden van de Raad zijn nogmaals langs de gerechten gegaan voor een tweede gesprekkenronde om ditmaal met rechters, raadsheren en overige medewerkers te spreken over oplossingsrichtingen. Naast een aantal andere onderwerpen was productiedruk wederom een centraal thema. Medewerkers van de Rechtspraak wijzen de huidige bekostigingssystematiek als belangrijke oorzaak van de ervaren productiedruk aan. Dit zou volgens de Raad niet zo mogen zijn: het bekostigingssysteem vormt weliswaar de basis voor de onderhandelingen over het budget met het ministerie van Veiligheid en Justitie, maar vervolgens kan de Rechtspraak dit budget naar eigen inzicht besteden, aldus de Raad. In elk geval zouden rechters en raadsheren bij hun procedurele keuzes geen rekening moeten houden met de bekostiging. ${ }^{11}$ En bovendien, zo gaf de Raad ook al in zijn eerdere brief te kennen, het vraagstuk mag niet vernauwd worden tot een discussie over financiën. ${ }^{12}$ 'Cruciaal is dat de rechters en raadsheren zelf consensus bereiken over wat in concrete situaties goede rechtspraak is. ${ }^{13}$

\section{Interne en externe spanningen in strategische positionering}

Met betrekking tot de strategische positionering van publieke organisaties kan zich een drietal spanningen voordoen: ${ }^{14}$

- een sturingsspanning tussen de eigen opvatting over de missie en het draagvlak voor die opvatting binnen de 'authorizing environment';

- een prestatiespanning tussen de missie van de organisatie en haar daadwerkelijke operationele capaciteit voor de realisatie van die missie;

- een autorisatiespanning tussen de feitelijke capaciteit en de werkwijze van de organisatie, en het draagvlak daarvoor binnen de authorizing environment.

Wanneer deze spanningen grafisch worden weergegeven, ontstaat het volgende beeld (zie figuur 2).

In het onderzoek naar de externe reputatie van de rechtspraak bleek dat er geen sprake is van grote sturingsspanningen en dat het draagvlak voor de missie van de Rechtspraak onomstreden is. Enige vorm van prestatiespanning werd wel geconstateerd. Door de onderzoekers wordt een dergelijke spanning evenwel tot op zekere hoogte onvermijdelijk geacht; in een samenleving met miljoenen mensen zullen er altijd meer geschillen en delicten zijn dan rechterlijke capaciteit om 
Figuur 2 Spanningen in de strategische positionering van publieke organisaties

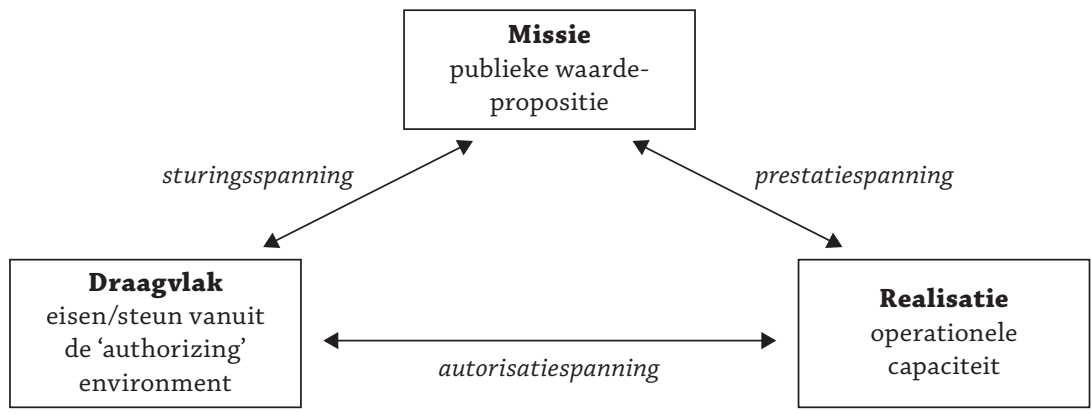

deze allemaal, tijdig en diepgaand te kunnen behandelen. ${ }^{15}$ Het beeld is evenwel dat hier geen sprake is van een onoverkoombaar probleem. Wél is er sprake van een

'autorisatiespanning tussen hoe het rechterlijk bedrijf (...) functioneert en het verwachtingspatroon van een 'goed opererende rechtspraak' dat onze gesprekspartners als norm hanteren'

In dit verband wordt opgemerkt dat de Rechtspraak er onvoldoende in slaagt om de gewenste doorlooptijden te realiseren en achterloopt als het gaat om digitalisering en technologische innovaties:

'[H]et beeld [rijst]op van een organisatie die een uiterst nastrevenswaardige missie op een over het algemeen rechtschapen en toegewijde maar op tal van punten aantoonbaar suboptimale en te reactieve en defensieve manier nastreeft.' 16

Daaraan is enerzijds de conclusie verbonden dat de Rechtspraak effectiever relaties moet onderhouden met en responsief moet zijn ten opzichte van een veeleisende maatschappelijke omgeving. Anderzijds maakt de kritiek duidelijk dat de Rechtspraak veel actiever moet uitdragen en communiceren wat er wordt bereikt.

De ontwikkelingen rondom het Manifest laten zien dat zich - naast de autorisatiespanning die wordt gesignaleerd in het onderzoek naar de reputatie van de rechtspraak - een interne autorisatiespanning voordoet. Daar waar de externe kritiek luidt dat de operationele capaciteit tekortschiet en de Rechtspraak wel wat efficiënter zou mogen opereren, klinkt als interne kritiek juist dat te veel wordt gestuurd op efficiency en dat de grens in dit opzicht is bereikt, sterker nog: overschreden. Door de nadruk op operationele capaciteit dreigt de interne onafhankelijkheid van de rechter in het gedrang te komen. Daarmee is er - vanuit intern perspectief - niet alleen sprake van een autorisatiespanning, maar hiermee ver- 
bonden is er ook sprake van een potentiële prestatiespanning. Immers, de rechters wijzen erop dat de operationele capaciteit niet voldoende is om de maatschappelijke opgave waar de Rechtspraak voor staat - kwalitatief goede rechtspraak - te realiseren.

\section{Een poging tot duiding: botsende paradigma's}

Het feit dat de interne en externe kritiek in zekere zin als tegenpolen van elkaar kunnen worden opgevat, kan beter worden begrepen door het functioneren van de rechtspraak te relateren aan het 'rechtsstatelijk paradigma' en het 'new public management-paradigma' ${ }^{17}$

Het rechtsstatelijk paradigma kenmerkt zich door het liberale uitgangspunt dat de Rechtspraak een belangrijke rol heeft ter verwezenlijking van de fundamentele vrijheidsrechten van burgers. De Rechtspraak biedt, met haar kenmerken van onafhankelijkheid en onpartijdigheid, een effectieve bescherming van de burger tegen overheidsinmenging. ${ }^{18}$ Rechtseenheid, rechtsgelijkheid en rechtszekerheid vormen belangrijke waarden bij de rechtvaardige wijze van beslechting van geschillen die een rechtsstaat kenmerkt. Voorts geldt in een rechtsstaat dat de institutionele 'onafhankelijkheid van de rechterlijke macht verzekert dat zij een daadwerkelijk tegenwicht kan bieden aan de macht van wetgever en bestuur' ${ }^{19}$ De rechtspraak is een staatsmacht die tegenover de andere staatsmachten een countervailing power moet zijn.

In het new public management-paradigma staan doelmatigheid en klantgerichtheid centraal. De theorie van new public management (NPM) deed in de jaren tachtig haar intrede en introduceerde meer economisch-bedrijfsmatige waarden in het publieke domein, zoals managementvaardigheden en competitie in de publieke dienstverlening. ${ }^{20}$ Daarbij was een belangrijk uitgangpunt dat

'het openbaar bestuur vooral beoordeeld moet worden op zijn prestatie, de output. Daartoe worden allerlei bedrijfskundige waarden en normen op de overheid toegepast, zoals prestatie-indicatoren, controlling, monitoring, outputmeting en kengetallen.' 21

Het 'NPM-denken' heeft ook voor de rechtspraak in Nederland consequenties. Mak geeft aan dat de NPM-waarden altijd wel randvoorwaarden voor het functioneren van de rechtspraak vormden, maar dat deze nu de basis zijn geworden voor specifieke eisen aan het rechterlijk handelen.

17 Paradigma wordt door Mak gedefinieerd als 'een samenhangend geheel van rechtsnormen, -beginselen, -waarden, -overtuigingen en -praktijken die ten grondslag liggen aan de discussie over de organisatie van de rechtspraak in een gegeven rechtsorde op een gegeven moment' (Mak 2008, p. 24).

18 Mak 2008, p. 29.

19 Mak 2008, p. 30.

20 Vergelijk Hood 1995.

21 Van den Heuvel e.a. 2002, p. 11. 
'De tijdige afhandeling van zaken is bijvoorbeeld een uitdrukkelijke gedragsnorm voor rechters geworden (...) en de Lamicienormen creëren druk op rechters en gerechten om een bepaalde 'productie' te halen.'22

De interne kritiek op de Rechtspraak kan voor een belangrijk deel worden begrepen als verzet tegen een - in de ogen van de ondertekenaars van het Manifest - te zwaar accent op de NPM-waarden. De interne critici wijzen op het risico dat dit ten koste kan gaan van de rechtsstatelijke waarden die de rechtspraak voorstaat. De rechtspraak wordt volgens hen te veel bestuurd als ware het een willekeurige organisatie, als een 'koekjesfabriek' - zoals vaak te beluisteren valt. Te weinig wordt volgens hen rekenschap gegeven van het feit dat de Rechtspraak opgevat moet worden als een institutie met een bijzondere taak in de moderne rechtsstaat. Daar waar een organisatie kan worden opgevat als 'a rational instrument engineered to do a job, a lean, no-nonsense system of consciously coordinated activities' is een institutie een organisatie 'infused with value beyond the technical requirements of the task at hand'. ${ }^{23}$ Bovendien is deze bijzondere institutionele karakteristiek ook nog eens constitutioneel verankerd. Onafhankelijkheid is daarmee niet alleen een empirisch kenmerk van werk en taak van de rechter als autonome professional, maar ook een normatief kenmerk met de zwaarst mogelijke juridische grondslag.

De oorzaak van een te groot accent op output wordt door de interne critici voor een belangrijk deel bij de Raad voor de rechtspraak gelegd en ook - zij het in mindere mate - bij de besturen van de gerechten en het ministerie van Veiligheid en Justitie. Daarbij zijn zij van mening dat de Raad te veel zou fungeren als de board van een groot bedrijf waarbij de 'rechtspraak wordt gemarginaliseerd tot een product dat op basis van productiecijfers gemanaged kan worden', waardoor de interne onafhankelijkheid in het gedrang komt. ${ }^{24}$

Maar niet alleen wordt volgens degenen die het Manifest onderschrijven te veel gestuurd op NPM-waarden, dit zou volgens hen ook gepaard gaan met te weinig aandacht voor rechtsstatelijke waarden. Immers, uit het Manifest spreekt de suggestie dat de Raad zich onvoldoende zou inzetten voor de externe onafhankelijkheid vanwege 'een voortdurende dialoog met de Haagse politiek'. Dit sentiment is door de Raad zelf ook gesignaleerd tijdens de tweede gesprekkenronde met de gerechten, zo blijkt uit de brief die de Raad na die bijeenkomsten opstelde. Een deel van medewerkers is van mening dat de Raad bij de politiek en het bestuur niet de belangen van de gerechten vertegenwoordigt. Vaak wordt gedacht dat de rol van de Raad omgekeerd is: dat hij de belangen van de minister behartigt bij de gerechten. Bij sommigen bestaat zelfs het beeld dat de Raad onderdeel is van het ministerie van Veiligheid en Justitie. ${ }^{25}$

22 Mak 2012.

23 Zie voor een nadere bespreking van het onderscheid tussen organisatie en institutie: Selznick 1992, p. 231 e.v.

24 Bron: Manifest.

25 Bron: brief leden Raad voor de rechtspraak, 8 juli 2013. 


\section{Perspectieven}

Wanneer we de externe en de interne kritiek met elkaar confronteren, lijken we op een patstelling te stuiten. De externe critici wijzen op de noodzaak de operationele capaciteit te vergroten, de interne critici wijzen er juist op dat het hoog tijd wordt dat de druk in dit opzicht van de ketel wordt gehaald. Wanneer aan een van beide groepen wordt tegemoetgekomen, neemt in het perspectief van de ander de kwaliteit van de rechtspraak (verder) af. Er is, kortom, een slimmere oplossing nodig die zowel tegemoetkomt aan de interne als aan de externe eisen en behoeften.

Een dergelijke intelligente oplossing begint in onze optiek met het vergroten van het institutioneel zelfbewustzijn van de Rechtspraak. Dit vraagt om reflectie op de waardenoriëntatie van de rechtspraak, of in de woorden van Selznick, reflectie op 'the business that we are really in'. ${ }^{26}$ Hoewel de buitenwacht van mening is dat de waardepropositie van de rechtspraak niet ter discussie staat, zijn wij van mening dat gegeven de veelheid van (uiteenlopende) eisen die aan de rechtspraak worden gesteld, een dergelijke heroriëntatie niet alleen waardevol maar ook noodzakelijk is. Het gaat daarbij niet zozeer om het definiëren welke waarden van belang zijn - evident is dat moet worden voldaan aan de rechtsstatelijke beginselen, en dat ook snelle en effectieve afhandeling van zaken van groot belang is. Het gaat er veeleer om tot een actuele en betekenisvolle invulling van de voor de rechtspraak relevante waarden te komen en om het vinden van de juiste balans met betrekking tot beide waardenoriëntaties. Die invulling heeft dan betrekking op het functioneren van de organisatie, op de vormgeving van sturing en op de interne en externe communicatie over deze waarden. Dit is des te meer van belang nu de Rechtspraak met het programma KEI (Kwaliteit en Innovatie) aan de vooravond van een belangrijke vernieuwing van proces en organisatie staat.

\section{Institutioneel zelfbewustzijn}

Duidelijkheid over de eigen waardenidentiteit maakt een wijze van besturen mogelijk '[that is] more fully purposive, more flexible, more responsive, more susceptible to leadership, more congenial to initiative at all levels'. ${ }^{27}$ Een stevig bewustzijn in dit opzicht maakt het mogelijk, en is nodig, om op een weloverwogen wijze te kunnen reageren op de uiteenlopende eisen die aan de rechtspraak worden gesteld. Dit is van belang in een tijd waarin, zo geeft Noordegraaf tijdens zijn Descarteslezing in 2010 aan, gezag niet vanzelfsprekend is, het gedrag van rechters onder een vergrootglas ligt, politici er niet voor terugdeinzen om voorstellen te doen die een mogelijke bedreiging vormen voor de onafhankelijke oordeelsvorming van rechters, en rechters in de media worden neergezet als wereldvreemd en niet wetend wat er in de samenleving leeft. Staande blijven in een dergelijk krachtenveld is alleen mogelijk als datgene waar de rechtspraak voor staat volledig doorleefd is, gedeeld wordt door de rechterlijke en niet-rechterlijke medewerkers, en met verve naar buiten wordt uitgedragen. Het is overigens ook 
alleen mogelijk als daarbij de nodige distantie wordt betracht ten opzichte van de samenleving, andere staatsinstellingen en de politiek. Dit om zicht te krijgen op wat er speelt, maar ook om zelf goed zichtbaar te zijn. ${ }^{28}$

In haar key note speech, tijdens een bijeenkomst in de winter van 2013 over rechtspraak en wetenschap, wees Pauline van de Meer Mohr onder de noemer 'existentieel gedoe' eveneens op het belang van zelfreflectie:

'Eerst moeten we onszelf terugvinden. Waar deden we het ook alweer voor? De rechterlijke macht weet zich overigens in goed gezelschap van wetenschappers, bankiers, politici, universiteitsbestuurders, kerkelijken en alle andere ambts- en gezagsdragers in dit land. Niets en niemand wordt prima facie meer vertrouwd of als competent beschouwd (...).

Deze opgave voor de aanscherping van de institutionele opgave ligt zowel bij de Raad en de gerechtsbesturen als bij de professionals zelf. In het navolgende formuleren we hiervoor kort enkele ideeën.

\section{Van management naar governance}

Voor de Raad en het bestuur van de gerechten vereist de existentiële opgave volgens Van der Meer Mohr dat het accent minder op management en meer op governance wordt gelegd. "Management' suggests a rational, efficiency-minded, goal-driven organization. This is the realm of administrative rather than political decisions.'29 Management loopt het risico dat de aandacht te zeer naar NPMwaarden en outputsturing gaat. En 'outputsturing leidt al gauw tot indicatorenfetisjisme waardoor irritaties toenemen (...) en het zicht op het einddoel vertroebelt'. ${ }^{30}$

Governance houdt in dat de eisen vanuit organisatieperspectief (gericht op output) verenigd worden met het institutieperspectief en er dus expliciet rekenschap wordt gegeven van de waardenidentiteit van de organisatie.

'To govern is (...) quite different from the rational coordination of specialized activities. Governance takes account of all the interests that affect the viability, competence and moral character of an enterprise. The strategies of governance are basically political. ${ }^{31}$

In het geval van de rechtspraak gaat governance dus niet alleen over structuur en functioneren, maar zeker ook over rechtspolitieke vragen vanuit het perspectief van de rechtspraak als deel van de trias politica.

De Raad heeft tegen deze achtergrond de NSOB gevraagd onderzoek te verrichten naar governance in de rechtspraak. Daarbij vindt reflectie plaats op de waardenoriëntatie en de taakopvatting van de rechtspraak. Het onderzoek zal in kaart 
brengen hoe kernwaarden het bestuur door de Raad en de gerechten dienen te schragen op een wijze die voorziet in betrokkenheid en vertrouwen van de professionals evenals in een onafhankelijke en evenwichtige verhouding tot de andere staatsmachten. Daarbij kan governance niet worden opgevat als een exclusieve verantwoordelijkheid van een specifiek orgaan of subsysteem, maar juist als een gedeelde opgave van organen en functionarissen van het individuele tot het collectieve niveau.

Het is daarbij de bijzondere verantwoordelijkheid van de Raad voor de rechtspraak om de institutie van de rechtspraak te positioneren in het maatschappelijke, politieke en bestuurlijke krachtenveld. De Raad moet dan weet hebben van de eisen en verwachtingen die vanuit de buitenwereld aan de rechtspraak worden gesteld en deze verenigen met uitgangspunten als autonomie en professionaliteit van rechters en raadsheren. Rechters staan zeker ook midden in de samenleving, gezien de uiteenlopende aspecten van de zaken waar zij dagelijks mee te maken hebben. Maar uiteindelijk werken rechters casusgericht en vormen zij hun oordeel, alles afwegende, in individuele gevallen.

\section{De professional aan zet}

Het aanscherpen van de maatschappelijke opgave van de rechtspraak is zeker geen taak van Raad en bestuurders alleen. Sterker nog, 'to infuse with value', het toebedelen met waarde, datgene wat een institutie onderscheidt van een organisatie, vraagt om toewijding en betrokkenheid van al degenen die behoren tot deze organisatie. ${ }^{32}$ Hier ligt een belangrijke verantwoordelijkheid voor de professional zelf. Welke ideeën hebben zij zelf over de door hen gesignaleerde problemen en welke rol kunnen zij zelf vervullen in de oplossing ervan?

Inmiddels hebben rechters en raadsheren de verantwoordelijkheid voor het beantwoorden van deze vragen opgepakt met het voornemen om professionele standaarden te ontwikkelen. Vanuit de verschillende landelijke overleggen vakinhoud (LOV's) zal voor de onderscheiden rechtsgebieden worden vastgesteld wat een goede beroepsuitoefening inhoudt. Uiteraard gelden er nu ook reeds kwaliteitscriteria, maar die zijn veelal impliciet en onuitgesproken. Door de ontwikkeling van professionele standaarden vindt discussie plaats en kan consensus ontstaan over wat goede rechtspraak inhoudt en op welke wijze processen binnen de rechtspraak het beste kunnen worden vormgegeven. ${ }^{33}$

\section{Samenvattend}

Het onderzoek naar de externe reputatie van de rechtspraak had als uitkomst dat de rechtspraak zich noch in een crisis bevindt, noch geldt als een onaantastbaar sterk merk. De externe kritiek op de rechtspraak richtte zich enerzijds op de organisatorische capaciteit van de rechtspraak, anderzijds werd naar voren gebracht

33 Vergelijk Bakker in het Jaarverslag Rechtspraak 2012. 
dat de Rechtspraak zich meer gelegen zou moeten liggen aan de externe beeldvorming en in dit opzicht proactiever zou moeten opereren.

Enkele maanden na publicatie van het rapport Reputaties gewogen verscheen een manifest opgesteld door enkele raadsheren uit Leeuwarden en ondersteund door ongeveer zevenhonderd rechters. Het Manifest gaf aanleiding tot de gedachte dat veeleer het interne draagvlak, in plaats van het externe, de rechtspraak voor problemen stelt. Belangrijke grieven uit het manifest betreffen de productiedruk en het risico op zowel schending van de interne als externe onafhankelijkheid. Daarmee deed de situatie zich voor dat met betrekking tot de operationele capaciteit van de rechtspraak door externen werd gesignaleerd dat er nog wel het nodige te verbeteren valt, terwijl intern aan de bel werd getrokken dat nog meer sturing op output de kwaliteit van rechtspraak in gevaar brengt. Wij hebben dit gepresenteerd als een botsing tussen new public management-waarden en rechtsstatelijke waarden. De oplossing is daarbij ons inziens niet meer van het een of meer van het ander, maar een slimme oplossing die pas geformuleerd kan worden na nadere reflectie op de waardenidentiteit van de rechtspraak, hetgeen institutioneel zelfbewustzijn vereist. Daarvoor is het nodig dat bestuurders (de Raad voorop) zich op het continuüm management-governance meer naar de pool van governance bewegen. Van de rechters en raadsheren vraagt dit dat zij zich door de ontwikkeling van professionele standaarden bezinnen op wat zij nu daadwerkelijk als goede rechtspraak definiëren. Dit alles vraagt om het verenigen van afstand, nodig voor reflectie, met betrokkenheid van bestuur én professional.

\section{Literatuur}

Frissen, P., 'Reputatie op afstand', Rechtstreeks 2012.

Frissen, P., P. 't Hart \& S. Sieckelinck, Reputaties gewogen. Beelden over de rechtspraak bij beslissers en publieke opinieleiders, Research Memoranda 2012(4).

Heuvel, J.H.J. van den, L.W.J.C. Huberts \& S. Verberk, Het morele gezicht van de overheid. Waarden, normen en beleid, Utrecht: Uitgeverij Lemma 2002.

Hood, Chr., "New public management" in the 1980s: variations on a theme', Accounting, Organizations and Society, 1995-20(2/3), p. 93-109

Krygier, M., Philip Selznick: Ideals in the world, Stanford: Stanford University Press 2012.

Mak, E., De rechtspraak in balans. Een onderzoek naar de rol van klassiek-rechtsstatelijke beginselen en 'new public management'-beginselen in het kader van de rechterlijke organisatie in Nederland, Frankrijk en Duitsland, Nijmegen: Wolf Legal Publishers 2008.

Mak, E., 'Rechtspraak en legitimiteit: rechtsstatelijke, economische en cognitieve factoren als basis voor vertrouwen in de Nederlandse rechtspraak', Bestuurswetenschappen 2012(1), p. 61-72.

Moore, M.H., Creating public value: Strategic management in government, New York: Harvard University Press 1995.

Selznick, Ph., The moral commonwealth. Social theory and the promise of community, Berkeley/ Los Angeles: University of California Press 1992.

Tulder, R. van \& A. van der Zwart, Reputaties op het spel. Maatschappelijk verantwoord ondernemen in een onderhandelingssamenleving, Utrecht: Het Spectrum 2003.

Overige bronnen: 
Suzan Verberk, Paul Frissen, Paul 't Hart \& Stijn Sieckelinck

Meer Mohr, P. van der, Tuinlieden gezocht, lezing tijdens de Dag van de Rechtspraak en Wetenschap, 12 februari 2013.

Noordegraaf, M., Van cases naar context - Nieuwe professionals gevraagd, lezing tijdens de Nacht van Descartes, 24 september 2010 (www.sg.uu.nl/opnames/najaar-2010/hetgezag-van-de-toga/avond-prof-dr-mirko-noordegraaf). 